\title{
Sensitivity of Mycosphaerella fijiensis from Banana to Trifloxystrobin
}

\author{
K. M. Chin, Novartis Crop Protection AG, Stein, Switzerland, CH-4332; M. Wirz, Novartis Agro, S.A., P.O. Box \\ 10141-1000 San José, Costa Rica; D. Laird, Novartis Crop Protection AG, Basle, Switzerland, CH-4002
}

\begin{abstract}
Chin, K. M., Wirz, M., and Laird, D. 2001. Sensitivity of Mycosphaerella fijiensis from banana to trifloxystrobin. Plant Dis. 85:1264-1270.

An ascospore germination method was developed and validated to assess the sensitivity of bulk samples of Mycosphaerella fijiensis to trifloxystrobin. Using this method, the sensitivity of 142 ascospore samples from banana plantations not treated with strobilurins was analyzed to establish a baseline of pathogen sensitivity. A bulk method was utilized for monitoring purposes because it avoids potential complications due to the isolation and propagation of single-spore isolates and enables the testing of larger samples. Following intensive use of strobilurins (6 to 11 applications per year) over 4 years, under conditions of high disease pressure and the absence of sanitary measures at a development site in Costa Rica, bulk samples with 50\% effective concentration $\left(\mathrm{EC}_{50}\right)$ resistance factors (RFs) in excess of 500 compared with the mean baseline sensitivity were detected. Single-ascospore isolates derived from spores germinating at the discriminatory dose of $3 \mu \mathrm{g} / \mathrm{ml}$ were also resistant, suggesting that the frequency of resistant individuals in bulk samples could be estimated from the relative numbers of ascospores growing at this dose. The resistance of selected isolates was confirmed in planta. In vitro tests with four resistant and two sensitive single-ascospore isolates collected from different locations and times indicated possible cross-resistance of trifloxystrobin to azoxystrobin, famoxadone, and fenamidone, but not to propiconazole.
\end{abstract}

Additional keywords: black Sigatoka, fungicide resistance

Black Sigatoka, caused by Mycosphaerella fijiensis Morelet, is a major disease of banana in almost all countries where the crop is commercially grown (15). The disease is effectively managed through the use of appropriate cultural methods and fungicide application. Intensive fungicide use and the polycyclic nature of the disease over a season of 8 to 9 months in many production environments can result in the exposure of large pathogen populations to selection by fungicides (11). To manage fungicide resistance risk, use strategies involving fungicide alternation have been adopted for the application of demethylation inhibitor and morpholine fungicides $(4,11)$. A new class of highly active fungicides, the strobilurins (e.g., trifloxystrobin and azoxystrobin), has recently been developed for the control of black Sigatoka (7).

Strobilurin fungicides work by inhibiting electron transport in mitochondrial respiration at the $\mathrm{Q}_{0}$ site of the cytochrome $\mathrm{bc}_{1}$ complex (complex III, Q-cytochrome $\mathrm{C}$ reductase). Resistance in fungi to strobilurins has been broadly attributed either

Corresponding author: K. M. Chin

E-mail: khoon_min.chin@syngenta.com

Current address of all authors: Syngenta Crop Protection AG, Basle, Switzerland, CH-4002.

Accepted for publication 3 September 2001.

Publication no. D-2001-1022-02R

(C) 2001 The American Phytopathological Society to a target site mutation or to the functioning of an alternative oxidation pathway $(5,17,18)$. In fungal pathogens of plants, alternative oxidase appears to cause relatively small reductions in sensitivity (10x in spore germination tests with Septoria tritici [18]; 60× in spore germination of Venturia inaequalis [10]), and did not affect performance in planta (9). As a result, some authors have considered that only in vivo studies are valid for the determination of resistance (9). On the other hand, detection of a target site mutation in Blumeria graminis (DC.) E.O. Speer (Erysiphe graminis DC.) f. sp. tritici Marchal, $M$. fijiensis (based on resistant isolates reported in this paper), and Plasmopara viticola (Berk. \& M.A. Curtis) Berl. \& de Toni in Sacc. $(2,5,13)$ has shown that resistant isolates carrying the same mutation have resistance factors ranging from several hundred- to several thousand-fold.

This paper reports on studies to define baseline sensitivity and to detect and characterize resistance of $M$. fijiensis to strobilurins in Central America. In vitro bulk sample tests were developed to test large numbers of ascospores using modest resources, thereby allowing the detection of rare frequencies of resistance and the tracking of changes in resistance frequencies in banana plantations. These tests were validated by their reproducibility and by the testing of selected single-spore isolates derived from the bulk samples, in conidial germination, mycelium growth, and in planta tests. Supplementary studies per- formed on the same isolates (12) have confirmed a target site change at the molecular level and excluded the influence of alternative oxidase on the resistance (12).

\section{MATERIALS AND METHODS}

The bulk sample method of ascospore collection and testing is similar to that previously described for sensitivity tests of $M$. fijiensis to demethylation inhibitors except that the proportion of spores that germinated was reported instead of measuring germ tube elongation (1). This is consistent with the reported high-level activity of strobilurins on spore germination (7). The method was validated by repeated tests with a reference isolate maintained on untreated plantain plants before its use for field monitoring. All tests were conducted at the Novartis laboratories in Costa Rica.

Test procedures with bulk samples. On average, 10 leaves with visible symptoms were collected at random from each banana sampling site (usually 1 to 2 ha), preferably under dry weather conditions. From these leaves, $102 \times 2 \mathrm{~cm}$ segments with necrotic tissue bearing perithecia were excised. The leaf segments were incubated under high relative humidity conditions in a plastic bag containing a moist paper towel for at least $48 \mathrm{~h}$ at a temperature of 26 to $28^{\circ} \mathrm{C}$ to allow ascospores to mature (during the rainy season the incubation period was extended to a minimum of $96 \mathrm{~h}$ because ascospore release tended to be delayed).

Aliquots $(95 \mathrm{ml})$ of $2 \%$ bacteriological agar (Bacto Agar, Difco, Detroit, MI) were autoclaved and cooled to $45^{\circ} \mathrm{C}$. A stock solution of trifloxystrobin at $50 \mu \mathrm{g} / \mathrm{ml}$ (formulated as a $7.5 \%$ emulsifiable concentrate) in $500 \mathrm{ml}$ of distilled water was prepared and used to obtain the following aqueous suspensions: $0.006,0.02,0.06$, $0.2,2,6$, and $20 \mu \mathrm{g} / \mathrm{ml}$ active ingredient. The final concentration range used for the spore germination test was prepared by adding $5 \mathrm{ml}$ of the corresponding aqueous stock to each 95-ml aliquot of sterilized agar solution to obtain concentrations of $0.0003,0.001,0.003,0.01,0.1,0.3$, and 1 $\mu \mathrm{g} / \mathrm{ml}$ active ingredient (in 1998 and 1999 an additional concentration of $3 \mu \mathrm{g} / \mathrm{ml}$ was included). These preparations were mixed well and dispensed into sterile glass petri dishes. Two plates per concentration were prepared for testing each sample.

After the incubation period, five leaf segments (for each of 2 plates) were removed from the plastic bag and stapled 
abaxial surface down to a $9 \times 9 \mathrm{~cm}$ piece of filter paper. The leaf segments were submerged for $5 \mathrm{~min}$ in distilled water, attached to the lid of a petri dish, and suspended over the fungicide-amended water agar. A minimum of $30 \mathrm{~min}$ was allowed for ascospore discharge, then the filter paper with the attached leaf segments was removed, and the plates were incubated at 26 to $28^{\circ} \mathrm{C}$ under natural light conditions on a laboratory bench for $48 \mathrm{~h}$.

Ascospore germination (presence of germ tube greater than $100 \mu \mathrm{m}$ in length) was determined visually using a microscope at $\times 200$ magnification. Three regions from the two agar plates were selected at random, and 50 ascospores were counted at each position giving a total of 150 spores per concentration. Spore counts were made systematically in transects, avoiding areas contaminated by other microorganisms or areas with excessive densities of ascospores. Results were expressed as the percentage of germinated ascospores.

$\mathrm{EC}_{50}$ (effective concentration required to cause a $50 \%$ reduction in germination relative to the control, at $0 \mu \mathrm{g}$ of trifloxystrobin per milliliter) and MIC values (minimum inhibitory concentration required to inhibit spore germination) were visually determined by plotting relative percent germination as a function of the $\log$ concentrations of the fungicide.

Test procedures with single ascospore isolates. Ascospores were collected as above except that the spores were discharged onto $1 \%$ water agar (Difco) amended with streptomycin sulfate at 200 $\mu \mathrm{g} / \mathrm{ml}$ (Fluka, Buchs, Switzerland). Single M. fijiensis ascospores were identified with the aid of a stereoscope and transferred with a sterile needle to petri dishes containing modified V8 agar $(100 \mathrm{ml}$ of V8 juice, $0.2 \mathrm{~g}$ of $\mathrm{CaCO}_{3}$, and $20 \mathrm{~g}$ of bacteriological agar [Difco] amended with streptomycin sulfate at $200 \mu \mathrm{g} / \mathrm{ml}$ ).

These cultures were incubated for 12 days at $22^{\circ} \mathrm{C}$ under continuous fluorescent light (Phillips TW58, $15 \mathrm{~W} / \mathrm{m}^{2}$ ). Individual colonies were then transferred to a test tube containing $200 \mathrm{ml}$ of $0.05 \%$ Tween 20 in sterile distilled water and stirred using a vortex mixer to release conidia. The conidia suspension was spread with a sterile rod over a petri dish containing modified V8 agar. This subculture was incubated for 12 days under the same conditions as described above to produce sufficient conidia for the assessment of sensitivity.

The test medium amended with trifloxystrobin was prepared as described above for the bulk sample ascospore tests, but in the concentration range $0.001,0.01,0.1,1$, and $10 \mu \mathrm{g} / \mathrm{ml}$. The petri dishes containing single ascospore lines were flooded with $0.05 \%$ Tween 20 in sterile distilled water to produce a conidia suspension of approximately $1 \times 10^{5}$ spores per milliliter. Test plates were inoculated with $200 \mu \mathrm{l}$ of the conidia suspension, sealed with Parafilm, and incubated at $22^{\circ} \mathrm{C}$ for $48 \mathrm{~h}$ in the dark. Conidial germination was assessed as described above for ascospore germination.

Test procedures with mycelium. For comparative studies with other active ingredients like the demethylation inhibitors (DMIs) that affect mycelium growth rather than spore germination, a method assessing mycelium growth was employed. Microtiter plates (24-well) were filled (1.5 $\mathrm{ml}$ per well) with potato dextrose agar (Oxoid, Basingstoke, Hampshire) contain- ing $0,0.0001,0.01,0.1,1$, or $10 \mu \mathrm{g}$ of each fungicide per milliliter, replicated four times in each plate. Mycelial suspensions were prepared from 25-day-old cultures of the fungus on V8 agar (V8 juice, $200 \mathrm{ml}$; $\mathrm{CaCO}_{3}, 3 \mathrm{~g}$; agar, Oxoid No. 3, $20 \mathrm{~g}$ ). Portions of colonized agar were homogenized ( $0.3 \mathrm{~g}$ of agar per milliliter of sterile distilled water using a sterile blender. The resultant mycelial suspension of each single ascospore isolate was filtered through mira cloth (250- $\mu \mathrm{m}$ pore size), and $200 \mu \mathrm{l}$ was added to each well. Following 14 days incubation at $24^{\circ} \mathrm{C}$ in the dark, the percent surface area in each well covered by mycelium growth was assessed visually. The $\mathrm{EC}_{50}$ values were determined as described above.

Test procedures for in planta test. A mycelium suspension was prepared as described above from each of four single ascospore cultures (mfcr110.99.10 and mfcr184.97.8 representing two resistant isolates, and mfcr185.97.3 and mfcr185.97.12 representing two sensitive isolates; all from in vitro ascospore and conidial germination tests). Inoculum was prepared by homogenizing 24-day-old cultures on modified V8 agar with $0.5 \%$ gelatin in sterile water $(0.3 \mathrm{~g}$ of agar culture per milliliter gelatin water). Two-month-old

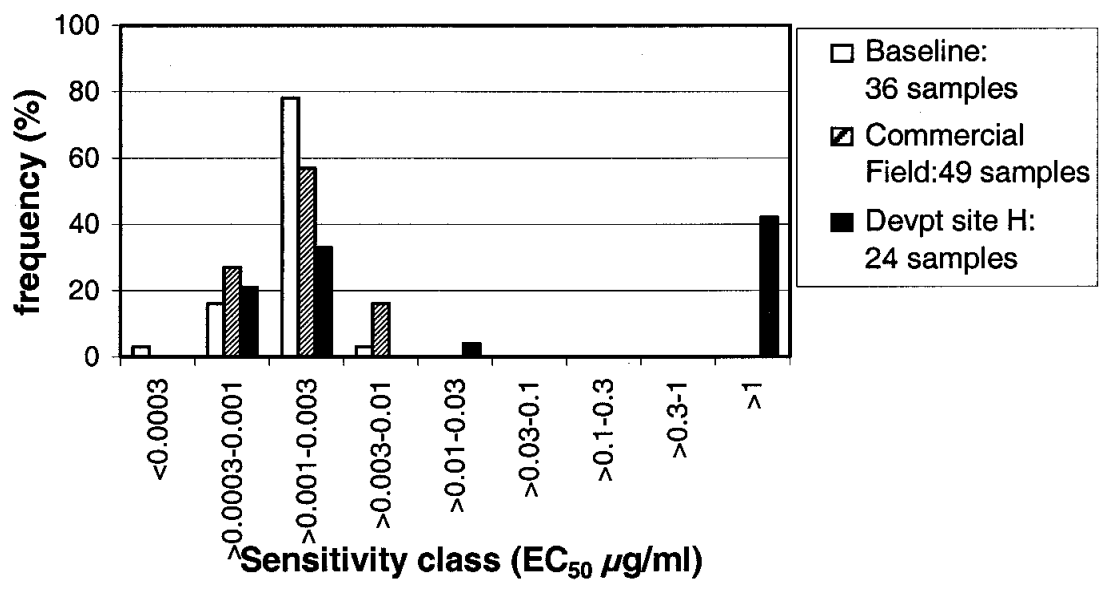

Fig. 1. Frequency distribution of sensitivity of bulk ascospore samples of Mycosphaerella fijiensis to trifloxystrobin in Costa Rica, 1997.

Table 1. Baseline sensitivity of Mycosphaerella fijiensis to trifloxystrobin in Central and South America (all bulk ascospore samples)

\begin{tabular}{|c|c|c|c|c|c|c|c|c|}
\hline \multirow[b]{2}{*}{ Country } & \multirow[b]{2}{*}{ Year } & \multirow[b]{2}{*}{ No. of samples } & \multicolumn{3}{|c|}{ EC $_{50}$ values $^{\mathrm{x}}(\mu \mathrm{g} / \mathrm{ml})$} & \multirow{2}{*}{$\begin{array}{l}\text { Range } \\
\text { factor }\end{array}$} & \multicolumn{2}{|c|}{$\mathrm{MIC}(\mu \mathrm{g} / \mathrm{ml})$} \\
\hline & & & Geometric mean $^{y}$ & Min & Max & & Min & Max \\
\hline \multirow[t]{3}{*}{ Costa Rica } & 1997 & 36 & $0.0016 \mathrm{a}$ & 0.0007 & 0.0060 & 9 & 0.010 & 1 \\
\hline & 1998 & 47 & $0.0022 \mathrm{a}$ & 0.0003 & 0.0080 & 27 & 0.010 & $>3^{z}$ \\
\hline & 1999 & 25 & $0.0020 \mathrm{a}$ & 0.0006 & 0.0120 & 20 & 0.100 & 3 \\
\hline Colombia & 1999 & 6 & $0.0028 \mathrm{a}$ & 0.0015 & 0.0060 & 4 & 1.000 & $>3^{z}$ \\
\hline Guatemala & 1999 & 12 & $0.0016 \mathrm{a}$ & 0.0005 & 0.0035 & 7 & 0.003 & 1 \\
\hline Belize & 1998 & 2 & $0.0028 \mathrm{a}$ & 0.0020 & 0.0040 & 2 & 1.000 & 1 \\
\hline Honduras & 1998-1999 & 11 & $0.0083 \mathrm{~b}$ & 0.0017 & 0.0500 & 29 & 0.100 & 3 \\
\hline Panama & 1999 & 3 & $0.0026 \mathrm{a}$ & 0.0017 & 0.0055 & 3 & 1.000 & 1 \\
\hline All & 1997-1999 & 142 & 0.0034 & 0.0003 & 0.0500 & 167 & 0.003 & 3 \\
\hline
\end{tabular}

${ }^{\mathrm{x}} \mathrm{EC}_{50}=50 \%$ effective concentration.

${ }^{y}$ Means followed by the same letter are not significantly different $(P>0.05)$ based on LSD test on log-transformed data, confirmed by linear contrasts and also by Scheffe's method.

${ }^{\mathrm{z}}$ Proportions of spores that germinated at $3 \mu \mathrm{g} / \mathrm{ml}$ were $0.3 \%$ in Costa Rica (1998) and 0.2\% in Colombia (1999). 
banana plants (cv. Grande Naine, Vitropica $\mathrm{SA}$, France) were planted in 9-cm-diameter pots. Plants with four fully expanded leaves were sprayed on both sides of the leaves with trifloxystrobin at 0,1 , or 10 $\mu \mathrm{g} / \mathrm{ml}$, treating two plants at each concentration. One day after treatment, the plants were inoculated by applying inoculum with a chromatography sprayer onto the abaxial leaf surfaces to maximum droplet retention. Immediately after inoculation, the plants were transferred to a climatic chamber maintained at $27^{\circ} \mathrm{C}$ day $/ 22^{\circ} \mathrm{C}$ night, 95\% RH, 16-h daylight. During the first 3 days, the plants were regularly wetted with a fine mist atomizer four times daily. Disease severity (percent diseased leaf area) on each of the four inoculated leaves was assessed 28 days after inoculation.

Sensitivity of baseline samples. One hundred and forty-two bulk ascospore samples were collected during 1997 to 1999 from regions not previously exposed to strobilurins in Costa Rica, Colombia, Guatemala, Honduras, Panama, and Belize, to establish a baseline sensitivity distribution to trifloxystrobin. The majority (108) of the baseline samples were from Costa Rica. A total of 34 bulk samples was obtained from Colombia, Guatemala, Belize, Honduras, and Panama. Mean $\mathrm{EC}_{50}$ values from each country were compared with an LSD test on log-transformed data and confirmed by linear contrasts and by Scheffe's method (8). Statistics were performed with SAS package version 6.12 (SAS Institute, Cary, NC).

Sensitivity at intensive testing sites. Monitoring was performed at two testing sites designated $\mathrm{H}$ and $\mathrm{R}$ in Costa Rica. Fungicide development work at site $\mathrm{H}$ had resulted in exposure of some plants to 6 to 11 applications of strobilurins per year from 1994 to 1997. Plants at site R had only been exposed to strobilurins for the first time in 1997. Prior to 1997, M. fijiensis sensitivity to trifloxystrobin was monitored at the $\mathrm{H}$ site by an external cooperator. In 1997, both sites $\mathrm{H}$ and $\mathrm{R}$ were sampled by Novartis personnel. A total of
24 bulk samples was collected from site $\mathrm{H}$, and 49 bulk samples from site $\mathrm{R}$, during September and October 1997. The field performance of trifloxystrobin was monitored at both sites. In 1998, after the confirmation of resistance at site $\mathrm{H}$, the infected plants were destroyed to prevent inoculum spread outside the area.

Sensitivity at commercial plantations. Sensitivities of an additional 49 (1997), 69 (1998), and 59 (1999) bulk samples from Costa Rica and 43 (1998 and 1999) from the other Central and South American countries were determined. These samples were collected from commercial and other development sites in areas treated with strobilurins.

Cross-resistance. Because DMIs do not significantly inhibit spore germination, cross-resistance assessments were performed using the mycelium growth test in order to have a common procedure for all fungicides.

Using single ascospore isolates (four resistant to trifloxystrobin, $\mathrm{EC}_{50}>10 \mu \mathrm{g} / \mathrm{ml}$; and two sensitive, $\mathrm{EC}_{50}$ values 0.002 and $0.007 \mu \mathrm{g} / \mathrm{ml}$, as defined in conidial germination tests), cross-resistance tests were conducted between trifloxystrobin and azoxystrobin (Amistar SC250), famoxadone (WG50, EZA12016), fenamidone (SC250, EZA6), and propiconazole (Tilt EC250), using the mycelium test procedure described above. The resistant isolates were obtained from the Novartis development site H in 1997 and from a commercial plantation in Costa Rica in 1999. The sensitive isolates were obtained from site $\mathrm{H}$ in 1997.

\section{RESULTS}

Results from five sets of tests with the same bulk isolate maintained on untreated plants showed highly reproducible sensitivity results. The $\mathrm{EC}_{50}$ values varied within the narrow range of 0.0012 to 0.0025 $\mu \mathrm{g} / \mathrm{ml}$, and MICs were consistently assessed at $0.3 \mu \mathrm{g} / \mathrm{ml}$ (data not shown).

Sensitivity of baseline samples. The results of sensitivity testing with these baseline samples showed an $\mathrm{EC}_{50}$ range of 0.0003 to $0.05 \mu \mathrm{g} / \mathrm{ml}$ with a highly consistent mean value of 0.002 to $0.003 \mu \mathrm{g} / \mathrm{ml}$ in most of the countries from which samples were obtained (Table 1). In Honduras, the mean $\mathrm{EC}_{50}$ was slightly but significantly higher at $0.008 \mu \mathrm{g} / \mathrm{ml}(P<0.05$, LSD test on log-transformed $\mathrm{EC}_{50}$ data, confirmed

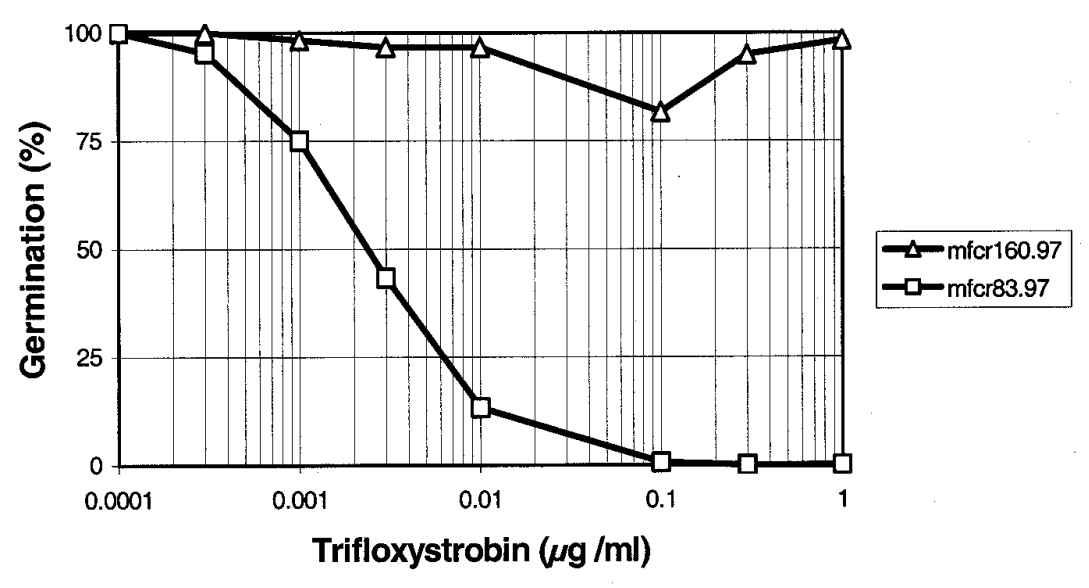

Fig. 2. Dose response curves of isolates of bulk ascospore samples of Mycosphaerella fijiensis sensitive (mfcr83.97) and resistant (mfcr160.97) to trifloxystrobin (ascospore germination test).

Table 2. Sensitivity of Mycosphaerella fijiensis bulk samples to strobilurins at intensive fungicide trial sites H and R, collected from trifloxystrobintreated and untreated banana trees

\begin{tabular}{|c|c|c|c|c|c|c|c|c|}
\hline Year & $\begin{array}{c}\text { Site }^{v} \\
\text { (trial) }\end{array}$ & Treatment & $\begin{array}{c}\text { Rate } \\
\text { (g a.i./ha) }\end{array}$ & $\begin{array}{c}\text { No. of } \\
\text { appl./year }\end{array}$ & $\underset{\mu \mathrm{g} / \mathrm{ml}}{\operatorname{Mean} \mathrm{EC}_{50}{ }^{\mathrm{w}}}$ & $\mathbf{R F}^{\mathbf{x}}$ & $\begin{array}{c}\% \text { resistant } \\
\text { spores }^{\mathrm{y}}\end{array}$ & $\begin{array}{l}\text { Disease } \\
\text { control }^{z}\end{array}$ \\
\hline 1994 & $\mathrm{H}(1)$ & Trifloxystrobin & 100 & 10 & $<0.001$ & $<1$ & NA & Excellent \\
\hline 1995 & $\mathrm{H}(1)$ & Trifloxystrobin & 100 & 7 & NA & NA & NA & Excellent \\
\hline 1996 & $\mathrm{H}(1)$ & Trifloxystrobin & 75 & 7 & $<0.0001$ & $<1$ & NA & Excellent \\
\hline 1997 & $\mathrm{H}(1)$ & Untreated & - & - & 0.0016 & $\sim 1$ & 0 & - \\
\hline 1997 & $\mathrm{H}(1)$ & Trifloxystrobin & 75 & 7 & $>1$ & $>500$ & 92 & Poor \\
\hline 1997 & $\mathrm{H}(2)$ & Untreated & - & - & 0.0017 & $\sim 1$ & 0 & - \\
\hline 1997 & $\mathrm{H}(2)$ & Trifloxystrobin & 75 & 7 & $>1$ & $>500$ & 91 & Poor \\
\hline 1997 & $\mathrm{R}$ & Trifloxystrobin & 90 & 7 & 0.002 & $\sim 1$ & 0 & Excellent \\
\hline \multicolumn{5}{|c|}{ Baseline mean (1997-1999) } & 0.0019 & & & \\
\hline
\end{tabular}

$\mathrm{v}^{\mathrm{S}}$ Site H received blocks of consecutive applications of strobilurins per year as indicated, development site R had no exposure to strobilurins prior to 1997.

${ }^{\mathrm{w}} \mathrm{EC}_{50}=50 \%$ effective concentration.

${ }^{x} \mathrm{RF}=$ resistance factor $=\mathrm{EC}_{50}$ of each test sample / $\mathrm{EC}_{50}$ of mean baseline (1997 to 1999) in Costa Rica.

y $\%$ of spores that germinated at $3 \mu \mathrm{g} / \mathrm{ml}$ based on single bulk samples except for $1997 \mathrm{H}(1)$, trifloxystrobin, two samples.

${ }^{z}$ Efficacy relative to untreated check by visual observation, excellent control indicated by $>80 \%$ control, and poor by less than $50 \%$ control; untreated checks had 54 and $57 \%$ of leaf area attacked respectively in $\mathrm{H}(1)$ and $\mathrm{H}(2)$. 
by linear contrasts). Most MIC values ranged from 1 to $3 \mu \mathrm{g} / \mathrm{ml}$, although in two cases they exceeded $3 \mu \mathrm{g} / \mathrm{ml}$ (i.e., rare spores could germinate at the highest concentration tested of $3 \mu \mathrm{g} / \mathrm{ml}$ ). In Costa Rica in 1998, and in Colombia in 1999, respectively, $0.3 \%$ and $0.2 \%$ of spores germinated at this concentration, indicating the possible existence of resistant individuals even in baseline samples. No resistant spores (able to germinate at 1 detected in baseline samples obtained in the other years.

Sensitivity at intensive testing sites. At the intensive fungicide screening site $\mathrm{H}$ (Costa Rica), 10 of 24 (42\%) bulk samples collected in 1997 showed high $\mathrm{EC}_{50}$ values significantly greater than those of the baseline isolates (or resistance factors more than $500 \times$ that of the Costa Rican mean baseline $\mathrm{EC}_{50}$ of $0.002 \mu \mathrm{g} / \mathrm{ml}$ ). These 24 samples therefore showed a bimodal and discontinuous frequency distribution of $\mathrm{EC}_{50}$ values; the 10 resistant samples appeared distinctly different from the sensitive samples collected in the same field or from baseline or other field samples (Fig. 1). At two locations in site $\mathrm{H}$ where performance was also evaluated, the frequencies of resistant spores in each of these bulk samples exceeded $90 \%$ ppm in 1997 or at 3 ppm in 1999) were

in plots treated with trifloxystrobin (Table 2).

No resistant strains had previously been detected at site $\mathrm{H}$ in samples collected from 1994 to 1996, and control of black Sigatoka with trifloxystrobin was greater than $90 \%$ in each of these years prior to 1997 (Table 2). No resistance was detected among the 49 samples collected from site R.

The resistant samples from site $\mathrm{H}$ were characterized by a lack of dose response to strobilurins (Fig. 2); the majority of ascospores $(>80 \%)$ germinated at the highest concentration tested of 1 or $3 \mu \mathrm{g} / \mathrm{ml}$ (initially tested at a maximum of $1 \mu \mathrm{g} / \mathrm{ml}$, and in subsequent tests germinated at $3 \mu \mathrm{g} / \mathrm{ml}$ ). Isolation of single ascospores germinating at the highest concentration (in 1997) of 1 $\mu \mathrm{g} / \mathrm{ml}$ produced only resistant isolates in conidial germination tests $\left(\mathrm{EC}_{50}\right.$ ranged from 3 to $>10 \mu \mathrm{g} / \mathrm{ml}$ ), suggesting that these spores represent resistant individuals (Table 3). In comparison, the reference sensitive isolate showed an $\mathrm{EC}_{50}$ of 0.0035 $\mu \mathrm{g} / \mathrm{ml}$. Resistance as measured by mean $\mathrm{EC}_{50}(>1 \mu \mathrm{g} / \mathrm{ml})$ of bulk samples and high frequencies of resistant spores tended to occur in treated plots at site $\mathrm{H}$ (Table 2). The reduction in performance of trifloxystrobin applied as a solo product was obvious in comparison with performance in previous years (1994 to 1996) at site H,

Table 3. Trifloxystrobin sensitivity of a bulk sample and single ascospore isolates of Mycosphaerella fijiensis collected from the intensive fungicide testing site H in 1997 (sensitivity of bulk isolates tested with ascospore germination test; sensitivity of single ascospore isolates tested with conidial germination test)

\begin{tabular}{lcc}
\hline Isolate & $\mathbf{E C}_{\mathbf{5 0}} \mathbf{x}(\boldsymbol{\mu g} / \mathbf{m l})$ & MIC $(\boldsymbol{\mu g} / \mathbf{m l})$ \\
\hline $\begin{array}{l}\text { Bulk sample } \\
\text { mfcr184.97 }\end{array}$ & $>1$ & $>1$ \\
$\begin{array}{l}\text { Single ascospore isolates }{ }^{\mathrm{z}} \\
\text { mfcr184.97.1 }\end{array}$ & $>10$ & $>10$ \\
mfcr184.97.2 & 3 & 10 \\
mfcr184.97.3 & 3 & $>10$ \\
mfcr184.97.4 & 3 & $>10$ \\
mfcr184.97.5 & 5 & $>10$ \\
mfcr185.97.4 (reference sensitive isolate) & 0.0035 & 1 \\
\hline x EC ${ }_{50}=50 \%$ effective concentration. & \\
${ }^{y}$ Original bulk sample from intensive testing site $\mathrm{H}$ in 1997, with $98 \%$ of ascospores able to germi- \\
nate at $1 \mu \mathrm{g} / \mathrm{ml}$. \\
${ }^{\mathrm{z}}$ Single ascospore lines derived from ascospores that germinated at $1 \mu \mathrm{g} / \mathrm{ml}$ in bulk test. Sensitivity \\
of these lines was tested with conidia at concentrations up to $10 \mu \mathrm{g} / \mathrm{ml}$ to confirm resistance.
\end{tabular}

or in comparison with performance at a sensitive location (site R) in the same year (actual data not shown).

Sensitivity in commercial plantations. Field monitoring of sensitivity in commercial banana production areas in Costa Rica showed no evidence of resistant bulk samples $\left(\mathrm{EC}_{50}>3 \mu \mathrm{g} / \mathrm{ml}\right)$ in most areas from 1997 to 1998 (Table 4), although resistant ascospores ( 0.1 to $1.3 \%$ ), able to grow at 1 or $3 \mu \mathrm{g} / \mathrm{ml}$, were detected as in baseline samples. However, at one location in Guapiles in 1999 (Table 4), three bulk samples with similar characteristics as resistant samples found at development site $\mathrm{H}$ were detected. The $\mathrm{EC}_{50}$ values of two samples exceeded $3 \mu \mathrm{g} / \mathrm{ml}$, and that of the third was $1.2 \mu \mathrm{g} / \mathrm{ml}$. All three samples contained ascospores capable of germinating at the discriminatory dose of $3 \mu \mathrm{g} / \mathrm{ml}$. Cultures of single ascospore lines derived from ascospores germinating at the highest concentration of $3 \mu \mathrm{g} / \mathrm{ml}$ produced only resistant isolates $\left(\mathrm{EC}_{50}>2 \mu \mathrm{g} / \mathrm{ml}\right.$, conidial germination test, Table 5). The frequency of ascospores germinating at $3 \mu \mathrm{g} / \mathrm{ml}$ therefore provided an estimate of frequencies (mean 69\%) of resistant individuals in these bulk samples. The detection of resistant ascospores was associated with the intensive, commercial use of strobilurins (14 applications from 1997 to 1999) at this location. However, practical resistance could not be confirmed because there were no obvious performance problems at this location, indicating that perhaps resistance evolution had been recent or that overall disease control had been maintained by the commercially imposed control measures.

No resistant $\left(\mathrm{EC}_{50}>3 \mu \mathrm{g} / \mathrm{ml}\right)$ bulk samples were found among limited numbers of samples from Colombia, Guatemala, Belize, Honduras, and Panama. However, a few ascospores $(0.25 \%)$ from Colombia were able to germinate at $3 \mu \mathrm{g} / \mathrm{ml}$ (Table 6 ). While only a limited number of bulk samples was assessed from each country, at least 150 ascospores were individually assessed per concentration. According to binomial theory $(2,16)$, in each case, the frequency of resistant spores was less than the detection limit of $2 \%$ at $P=0.05$.

Table 4. Field sensitivity of Mycosphaerella fijiensis to trifloxystrobin in commercial banana plantations in Costa Rica, 1997 to 1999

\begin{tabular}{|c|c|c|c|c|c|c|c|c|}
\hline \multirow[b]{2}{*}{ Year } & \multirow[b]{2}{*}{$\begin{array}{c}\text { No. of } \\
\text { samples }\end{array}$} & \multicolumn{3}{|c|}{ EC $_{50}$ values $^{x}(\mu \mathrm{g} / \mathrm{ml})$} & \multicolumn{4}{|c|}{$\mathrm{MIC}(\mu \mathrm{g} / \mathrm{ml})$} \\
\hline & & $\begin{array}{c}\text { Geometric } \\
\text { mean }\end{array}$ & Min & Max & Min & Max & $\begin{array}{c}\% \text { samples } \\
\mathrm{EC}_{50}>1(\mu \mathrm{g} / \mathrm{ml})\end{array}$ & $\begin{array}{c}\% \text { resistant } \\
\text { spores }^{y}\end{array}$ \\
\hline 1997 & 49 & 0.0018 & 0.0006 & 0.008 & 0.1 & $>1$ & 0 & 1.3 \\
\hline 1998 & 69 & 0.0020 & 0.0006 & 0.1 & 0.1 & $>3$ & 0 & 0.1 \\
\hline 1999 & 59 & - & 0.0004 & $>3$ & 0.1 & $>3$ & 5 & 3.4 \\
\hline $\begin{array}{c}\text { Baseline } \\
1997-1999\end{array}$ & 108 & 0.0019 & 0.0003 & 0.012 & 0.0 & $>3$ & 0 & 0.12 \\
\hline \multicolumn{9}{|c|}{ Individual samples from Guapiles, Costa Rica in $1999^{z}$, with $\mathrm{EC}_{50}>1$} \\
\hline 1999 & $\operatorname{mfcr} 110$ & & & 1.2 & & $>3$ & & 36 \\
\hline 1999 & mfcr141 & & & $>3$ & & $>3$ & & 83 \\
\hline 1999 & $\operatorname{mfcr} 146$ & & & $>3$ & & $>3$ & & 87 \\
\hline
\end{tabular}

${ }^{\mathrm{x}} \mathrm{EC}_{50}=50 \%$ effective concentration.

y Percentage of spores that germinate with trifloxystrobin at $1 \mu \mathrm{g} / \mathrm{ml}$ (1997) and $3 \mu \mathrm{g} / \mathrm{ml}$ (1998-1999).

${ }^{\mathrm{z}}$ Total of seven bulk samples tested, $\min \mathrm{EC}_{50}=0.025 \mu \mathrm{g} / \mathrm{ml}, \max \mathrm{EC}_{50}>3 \mu \mathrm{g} / \mathrm{ml}$. 
The sensitivity of two resistant isolates, mfcr110.99.10 (the commercial site, 1999) and mfcr184.97.8 (site H, 1997), from the in vitro germination tests was confirmed in planta in comparison with two sensitive isolates, mfcr185.97.3 and mfcr185.97.12 (Fig. 3). The resistant isolates showed little dose response, compared with the steep response of the sensitive isolates within the range tested. Even though the limited number of concentrations $(0,1$, and $10 \mu \mathrm{g} / \mathrm{ml})$ tested was insufficient to determine precise $\mathrm{EC}_{50}$ values, the data indicate that those of both resistant isolates would exceed 10 $\mu \mathrm{g} / \mathrm{ml}$, whereas those of the two sensitive isolates were in the range of 0.3 to 0.4 $\mu \mathrm{g} / \mathrm{ml}$, with MICs of 1 to $10 \mu \mathrm{g} / \mathrm{ml}$.

Cross-resistance. Results from the mycelium growth test with single ascospore lines, four resistant to trifloxystrobin (two derived from samples taken in 1997 from intensive site $\mathrm{H}$ and two from the commercial site in Costa Rica in 1999) and two sensitive, were consistent with those ob- tained with conidial germination tests and suggest that there could be cross-resistance of trifloxystrobin to azoxystrobin, famoxadone, and fenamidone, but not between trifloxystrobin and propiconazole (Table 7). Based on the $\mathrm{EC}_{50}$ values obtained, all resistant isolates to trifloxystrobin were resistant, and both sensitive isolates to trifloxystrobin were sensitive to each of the other products, except propiconazole. In the case of propiconazole, isolates with shifted or nonshifted sensitivity bore no apparent relationship to their resistance or sensitivity to trifloxystrobin. Correlation analyses are not presented because in a number of cases the $\mathrm{EC}_{50}$ values observed exceeded the maximum dose tested of 10 $\mu \mathrm{g} / \mathrm{ml}$ and could not therefore be precisely determined. Although the number of isolates studied was small, the use of resistant isolates originating from different regions in different years supports the indication of cross-resistance between trifloxystrobin, azoxystrobin, famoxadone, and fenamidone.

Table 5. Sensitivity of single ascospore isolates of Mycosphaerella fijiensis from a bulk isolate from a commercial site in Costa Rica in 1999 (sensitivity of bulk isolates tested with ascospore germination test; sensitivity of single ascospore isolates tested with conidial germination test)

\begin{tabular}{lcc}
\hline Isolate & $\mathbf{E C}_{\mathbf{5 0}} \mathbf{x}(\boldsymbol{\mu g} / \mathbf{m l})$ & MIC $(\boldsymbol{\mu g} / \mathbf{m l})$ \\
\hline $\begin{array}{l}\text { Bulk sample } \\
\text { mfcr110.99 }\end{array}$ & 1.2 & $>3$ \\
Single spore isolates & & \\
mfcr110.99.3 & & $>10$ \\
mfcr110.99.4 & 3.00 & $>10$ \\
mfcr110.99.5 & 7.00 & $>10$ \\
mfcr110.99.6 & 6.00 & $>10$ \\
mfcr110.99.7 & 4.50 & $>10$ \\
mfcr110.99.8 & $>10$ & $>10$ \\
mfcr110.99.9 & $>10$ & $>10$ \\
mfcr110.99.10 & 5.50 & $>10$ \\
mfcr110.99.13 & $>10$ & $>10$ \\
mfcr110.99.14 & 2.30 & $>10$ \\
mfcr110.99.16 & $>10$ & $>10$ \\
mfcr110.99.18 & $>10$ & $>10$ \\
mfcr110.99.20 & 10 & $>10$ \\
mfcr110.99.21 & $>10$ & $>10$ \\
mfcr110.99.22 & $>10$ & $>10$ \\
mfcr110.99.23 & 2.50 & $>10$ \\
mfcr110.99.24 & 3.6 & $>10$ \\
mfcr110.99.25 & $>10$ & $>10$ \\
mfcr110.99.26 & 2.5 & $>10$ \\
mfcr110.99.28 & $>10$ & $>10$ \\
\hline
\end{tabular}

${ }^{\mathrm{x}} \mathrm{EC}_{50}=50 \%$ effective concentration.

y Original bulk sample from commercial site in Costa Rica in 1999, with $36 \%$ of ascospores that germinated with trifloxystrobin at $3 \mu \mathrm{g} / \mathrm{ml}$.

${ }^{\mathrm{z}}$ Single ascospore lines derived from ascospores that germinated with trifloxystrobin at $3 \mu \mathrm{g} / \mathrm{ml}$ in bulk test.

\section{DISCUSSION}

The monitoring method of testing bulk ascospore samples rather than single spore isolates was introduced with the objective of developing a simple, yet sensitive method for wide applicability in tropical regions without access to dedicated laboratories; and to minimize chances of pathogen variation through repeated subculturing. The assessment of large numbers of spores allows the detection of rare individuals without having to grow and test the equivalent number of single spore isolates (16). Furthermore, since ascospores are the main source of inoculum in banana plantations (14), testing of these spores is likely to be more relevant than testing conidia or mycelia produced from cultures. Results presented indicate that quantitative data on frequencies of resistant individuals can be estimated from the frequencies of resistant spores detected in bulk samples.

Baseline sensitivity in all countries surveyed was within the $\mathrm{EC}_{50}$ range of 0.0003 to $0.05 \mu \mathrm{g} / \mathrm{ml}$ with MICs in almost all cases (Table 1) of trifloxystrobin at 1 to 3 $\mu \mathrm{g} / \mathrm{ml}$. The significance of rare spores able to grow at $3 \mathrm{ppm}$ in Costa Rica in 1998 $(0.3 \%)$ and in Colombia in $1999(0.2 \%)$ is unclear because isolations were not attempted. However, the current evidence suggests that these could constitute rare resistant individuals in unselected populations. The slightly higher mean sensitivity in Honduras $(0.008 \mu \mathrm{g} / \mathrm{ml})$ compared with other countries $(0.002$ to $0.003 \mu \mathrm{g} / \mathrm{ml})$ was statistically significant $(P<0.05)$ but not considered to be biologically significant because MICs remained within the range of 1 to $3 \mu \mathrm{g} / \mathrm{ml}$.

Field monitoring in Belize, Costa Rica, Colombia, Honduras, and Panama suggests that $M$. fijiensis populations in commercial plantations were largely sensitive to strobilurins in 1997 to 1999 . Exceptional findings from an experimental farm and from a commercial area in Costa Rica with an extended history of strobilurin exposure indicate a potential for pathogen adaptation to strobilurins.

Consistent with recent findings on Blumeria graminis $(2,13)$, resistance in $M$. fijiensis to strobilurins apparently also occurs due to a target site mutation leading to single amino acid change from glycine to alanine at position G143 of the cytochrome $b$ gene (13). This change resulted

Table 6. Field sensitivity of Mycosphaerella fijiensis to trifloxystrobin in Central and South America (excluding Costa Rica)

\begin{tabular}{|c|c|c|c|c|c|c|c|c|}
\hline \multirow[b]{2}{*}{ Country } & \multirow[b]{2}{*}{ Year } & \multirow[b]{2}{*}{$\mathbf{N}^{\mathbf{y}}$} & \multicolumn{3}{|c|}{ EC $_{50} \operatorname{values}^{x}(\mu \mathrm{g} / \mathrm{ml})$} & \multicolumn{2}{|c|}{ MIC ( $\boldsymbol{\mu g} / \mathrm{ml})$} & \multirow{2}{*}{$\begin{array}{c}\% \text { resistant } \\
\text { spores }^{\mathrm{z}}\end{array}$} \\
\hline & & & Geometric mean & Min & Max & Min & Max & \\
\hline Colombia & 1999 & 28 & 0.007 & 0.0010 & 0.3000 & 1.000 & $>3$ & 0.25 \\
\hline Guatemala & 1998-1999 & 3 & 0.0067 & 0.0040 & 0.0170 & 0.010 & 3.0 & 0 \\
\hline Belize & 1998 & 4 & 0.0034 & 0.0015 & 0.0100 & 1.000 & 3.0 & 0 \\
\hline Honduras & 1999 & 7 & 0.005 & 0.0015 & 0.0600 & 1.000 & 3 & 0 \\
\hline Panama & 1999 & 1 & 0.0030 & 0.0030 & 0.0030 & 1.000 & 1.0 & 0 \\
\hline
\end{tabular}

${ }^{\mathrm{x}} \mathrm{EC}_{50}=50 \%$ effective concentration.

y $\mathrm{N}=$ number of bulk samples tested.

z $\%$ ascospores able to germinate with trifloxystrobin at $3 \mu \mathrm{g} / \mathrm{ml}$. 
in a new phenotype, which was clearly distinguishable from that of baseline isolates by exhibiting little to no dose response to the fungicides in ascospore germination, conidial germination, mycelium growth, and in planta tests. Conidia of single ascospore lines derived from ascospores that germinated at the discriminatory concentration of 1 (1997) or $3 \mu \mathrm{g} / \mathrm{ml}$ (1998 and 1999) also had high $\mathrm{EC}_{50}$ values in subsequent spore germination tests, the bulk samples. Based on these results, counts of ascospores from bulk samples able to germinate at a discriminatory dose may provide an indication of the frequencies of resistant individuals in these bulk samples.

Chin et al. (2) showed that in $B$. graminis, sensitive mean $\mathrm{EC}_{50}$ values of bulk samples could conceal the occurrence of rare individuals that are resistant. This study supports the conclusion that measurements of the frequencies of resistant spores, in addition to mean $\mathrm{EC}_{50}$ values, are critical for assessing the sensitivity of field populations to strobilurins.

Resistant individuals were detected from bulk field samples. Resistance occurred in $42 \%$ of the 24 bulk samples The frequency of resistant ascospores in some of these samples exceeded $90 \%$ and was associated with a loss of product performance. This would suggest a significant level of epidemiological competence of adapted strains in the presence of selection pressure. confirming the resistance of individuals in tested at the development site $\mathrm{H}$ in 1997.

There was some evidence indicating possible cross-resistance between trifloxystrobin and other strobilurins, famoxadone and fenamidone, but not to propiconazole, suggesting the potential value of demethylation inhibitors in resistance management programs for strobilurins. The indication of cross-resistance between strobilurins and famoxadone is consistent with a recent report (6) that although famoxadone is not a strobilurin, it inhibits mitochondrial electron transfer at the $\mathrm{Q}_{\mathrm{o}}$ site of cytochrome $b_{1}$, as do the strobilurins.

The findings described in this paper indicate a significant risk of resistance in $M$. fijiensis to strobilurins. While the fitness and success of adapted pathotypes under commercial conditions are as yet unclear, modifying factors (3) need to be implemented to minimize the risk of resistance. Strobilurin fungicides and other $Q_{0}$ inhibitors should be applied at effective rates and correct application timing and intervals. Since 7 to 10 blocked applications per year under specific conditions of severe disease pressure and poor sanitation can lead to the development of resistance, it is suggested that the total number of applications should not exceed four per year. A defined strobilurin-free period could also be implemented to allow for the possibility of remission of resistance frequencies in the absence of selection. Strobilurins and other $\mathrm{Q}_{\mathrm{o}}$ inhibitors should be applied in alternation with effective demethylation inhibitor and contact fungicides. Additional risk modifiers should

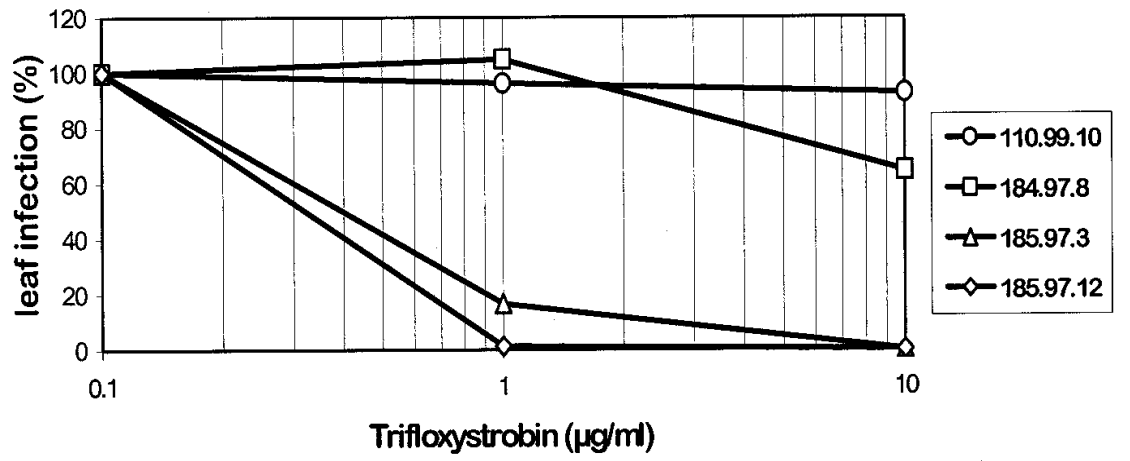

Fig. 3. Dose response curves of single ascospore isolates of Mycosphaerella fijiensis sensitive (mfcr185.97.3 and mfcr185.97.12) and resistant (mfcr110.99.10 and mfcr184.97.8) to trifloxystrobin assessed 28 days after inoculation (in planta test).

Table 7. Relationships between sensitivity to trifloxystrobin and azoxystrobin, famoxadone, fenamidone, and propiconazole in selected isolates of Mycosphaerella fijiensis

\begin{tabular}{lccccc}
\hline & \multicolumn{5}{c}{ EC $_{\mathbf{5 0}}$ values $^{\mathbf{y}}(\boldsymbol{\mu g} / \mathbf{m l})$} \\
\cline { 2 - 6 } Isolate & Trifloxystrobin & Azoxystrobin & Famoxadone & Fenamidone & Propiconazole \\
\hline mfcr 97.4 & $>10(\mathrm{R})^{\mathrm{z}}$ & $>10(\mathrm{R})$ & $>10(\mathrm{R})$ & $>10(\mathrm{R})$ & $0.3(\mathrm{~S})$ \\
mfcr 97.8 & $>10(\mathrm{R})$ & $>10(\mathrm{R})$ & $>10(\mathrm{R})$ & $>10(\mathrm{R})$ & $0.22(\mathrm{~S})$ \\
mfcr 10 & $>10(\mathrm{R})$ & $>10(\mathrm{R})$ & $>10(\mathrm{R})$ & $>10(\mathrm{R})$ & $1.7(\mathrm{R})$ \\
mfcr 99.17 & $>10(\mathrm{R})$ & $>10(\mathrm{R})$ & $>10(\mathrm{R})$ & $>10(\mathrm{R})$ & $6.8(\mathrm{R})$ \\
mfcr 97.25 & $0.0067(\mathrm{~S})$ & $0.058(\mathrm{~S})$ & $0.07(\mathrm{~S})$ & $0.5(\mathrm{~S})$ & $0.14(\mathrm{~S})$ \\
mfcr 97.30 & $0.0019(\mathrm{~S})$ & $0.027(\mathrm{~S})$ & $0.03(\mathrm{~S})$ & $0.3(\mathrm{~S})$ & $0.17(\mathrm{~S})$ \\
\hline
\end{tabular}

y $\mathrm{EC}_{50}=50 \%$ effective concentration.

${ }^{\mathrm{z}}$ Sensitive (S) or resistant $(\mathrm{R})$ to fungicide, based on $\mathrm{EC}_{50}$ values. include good crop management practices, especially sanitation procedures to reduce inoculum pressure, and local synchronization of application of fungicides with a similar mode of action to avoid overlapping exposure periods.

\section{ACKNOWLEDGMENTS}

We acknowledge the assistance of all colleagues in Novartis (particularly W. Ruess for field support and D. R. Wille for statistical advice) who have contributed to this paper and to $\mathrm{H}$. Hoffmann, who was responsible for the performance trials in Costa Rica. We thank R. Madrigal and R. Astúa for their technical assistance.

\section{LITERATURE CITED}

1. Chin, K. M., Arroyo, T., Forster, B., and Steden, C. 1996. Sensitivity of Mycosphaerella fijiensis to demethylation inhibitors in Central America: Testing methodology and cross-resistance. Pages 413-421 in: Proc. XII Réunion Arcorbat, Oct. 28-Nov. 1, 1996, République Dominicaine.

2. Chin, K. M., Chavaillaz, D. C., Kaesbohrer, M., Staub, T., and Felsenstein, F. G. 2001 Characterizing resistance risk of Erysiphe graminis f. sp. tritici to strobilurins. Crop Prot. 20:87-96.

3. EPPO. 2000. Guideline for the efficacy evaluation of plant protection products PP1/213(1). EPPO Bull. 29(3).

4. FRAC. 1998. Fungicide use guidelines. Fungicide Resistance Action Committee, Global Crop Protection Federation, Brussels, Belgium.

5. Gisi, U., Chin, K. M., Knapova, G., KuengFaerber, R., Mohr, U., Parisi, S., Sierotsky, H. and Steinfeld, U. 2000. Recent developments in elucidating modes of resistance to phenylamide, DMI and strobilurin fungicides. Crop Prot. 19:863-872.

6. Jordan, D. B., Livingston, R. S., Bisaha, J. Duncan, K. E., Pember, S. O., Picolleli, M. A., Schwartz, R. S., Sternberg, J. A., and Tang, X.-S. 1999. Mode of action of famoxadone. Pestic. Sci. 55:105-111

7. Margot, P., Huggenberger, F., and Amrein, J. 1998. CGA 279202: A broad spectrum strobilurin fungicide. Pages 375-382 in: The 1998 Brighton Conference - Pests and Diseases $5 \mathrm{~A}-8$.

8. Montgomery, D. C. 1984. Design and Analysis of Experiments. 2nd ed. John Wiley \& Sons, New York.

9. Olaya, G., and Köller, W. 1999. Diversity of kresoxim-methyl sensitivities in baseline populations of Venturia inaequalis. Pestic. Sci. 55:1083-1088.

10. Olaya, G., Zheng, D., and Köller, W. 1998. Differential responses of germinating Ven turia inaequalis conidia to kresoxim-methyl. Pestic. Sci. 54:230-236.

11. Romero, R. A., and Sutton, T. B. 1997. Sensitivity of Mycosphaerella fijiensis, causal agent of black Sigatoka of banana, to propiconazole. Phytopathology 87:96-100.

12. Sierotzki, H., Parisi, S., Steinfeld, U., Tenzer, I., Poirey, S., and Gisi, U. 2000. Mode of resistance to respiration inhibitors at the cytochrome bc1 enzyme complex of Mycosphae rella fijiensis field isolates. Pest Manage. Sci. 56:833-841.

13. Sierotzki, H., Wullschleger, J., and Gisi, U. 2000. Point mutation in cytochrome b gene conferring resistance to strobilurin fungicides in Erysiphe graminis f. sp. tritici field isolates. Pestic. Biochem. Physiol 68:107-112.

14. Stover, R. H. 1980. Sigatoka leaf spots of bananas and plantains. Plant Dis. 64:750-755.

15. Stover, R. H., and Simmonds, N. W. 1987. 
Bananas, 3rd ed. Longman Scientific \& Technical, New York.

16. Wolfe, M. S. 1982. Dynamics of the pathogen population in relation to fungicide resistance. Pages 139-148 in: Fungicide Resistance in Crop Protection. J. Dekker and S. G. Geor- gopoulos, eds. Centre for Agricultural Publishing and Documentation, Wageningen, Netherlands.

17. Zheng, D., and Köller, W. 1997. Characterization of the mitochondrial cytochrome $b$ gene from Venturia inaequalis. Curr. Genet.
$32: 361-366$

18. Ziogas, B. N., Baldwin, B. C., and Young, J. E. 1997. Alternative respiration: A biochemical mechanism of resistance to azoxystrobin (ICIA5504) in Septoria tritici. Pestic. Sci. 50:28-34. 